\title{
Bioterrorismo, riscos biológicos e as medidas de biossegurança aplicáveis ao Brasil
}

\section{1 Dora Rambauske, ${ }^{2}$ Telma Abdalla de Oliveira Cardoso, \\ ${ }^{3}$ Marli Brito Moreira de Albuquerque Navarro I}

Resumo: A história registra o uso de patógenos como potencializadores de recursos bélicos. Considerando os eventos bélicos da contemporaneidade, observase a formulação de projetos voltados para elaboração tecnológica sofisticada. Nessa categoria se incluem as armas biológicas, vinculadas aos programas de caráter coercitivo conhecidos como guerras biológicas, que pertencem à lógica da ameaça assimétrica, não definindo território e gerando repercussōes econômicas, políticas e sociopsicológicas devastadoras. Esses eventos demandam a elaboração de planos que contemplem o risco, incluindo a capacitação de recursos humanos, investimentos na identificação de materiais empregados em bioterrorismo e também em equipamentos de segurança. Objetiva-se neste artigo discutir a associação entre patógenos, seu potencial de risco e eficácia para o emprego em estratégias de bioterrorismo, destacando as medidas de biossegurança necessárias. Utiliza-se a revisão integrativa para a construção de análises de contextos de risco. O levantamento bibliográfico compreendeu o período 1990/2010, nas bases de dados ISI, LILACS, SciELO e PubMed. Demonstra-se a importância do envolvimento e da capacitação dos profissionais na identificação de agentes biológicos com potencial de risco, considerando que o bioterrorismo pode resultar na sobrecarga dos sistemas de saúde. A biossegurança orienta os procedimentos que devem ser adotados para a contenção dos patógenos, visando ao controle dos riscos.

\author{
1 Mestre em Biossegurança em \\ Saúde pelo Instituto de Pesquisa \\ Clínica Evandro Chagas, Brasil. \\ Chefe da seção de defesa \\ biológica do Centro Tecnológico \\ do Exército. Endereço eletrônico: \\ dora.rambauske@gmail.com \\ 2 Doutora em Saúde Pública \\ pela FIOCRUZ - Escola \\ Nacional de Saúde Pública, \\ Brasil. Pesquisadora da Escola \\ Nacional de Saúde Pública \\ (ENSP-FIOCRUZ). Professora \\ dos cursos de pós-graduação \\ da ESNP. Endereço eletrônico: \\ abdalla@fiocruz.br \\ ${ }^{3}$ Doutora em História \\ Contemporânea - Université \\ Paris X. Pesquisadora da \\ Escola Nacional de Saúde \\ Pública da FIOCRUZ. Participa \\ como docente em cursos de \\ pós-graduação da FIOCRUZ \\ Endereço eletrônico: \\ mnavarro@fiocruz.br
}


Os flagelos provocados por doenças fazem parte da história da humanidade. A peste negra, que devastou a Europa no século XIV, permanece como símbolo do horror. Depois do registro da peste bubônica na Idade Média, "peste" passou a significar qualquer dano de grande potencial de risco.

Considerando a lógica das ameaças assimétricas, a disseminação intencional de doenças de potencial epidêmico ocorre através da dispersão de agentes patogênicos com a finalidade de agredir, incapacitar ou matar, visando conquistar territórios e expandir domínios. Contudo, os conflitos convencionais também registraram a utilização desse recurso como arma. Silva (2001) destaca como um dos exemplos mais antigos encontrados na literatura o uso fezes de animais em flechas fabricadas pelo homem de Neanderthal. Esse mesmo procedimento foi utilizado durante a guerra do Vietnã (1959-1975), quando uma estaca de madeira ou de bambu contaminada com fezes, denominada estaca punji, era distribuída, com a ponta para fora do solo, no caminho das tropas inimigas (CHRISTOPHER et al., 1997). Ressalta-se que inicialmente os agentes biológicos foram empregados de forma intuitiva e muito rudimentar, deixando dúvidas sobre sua eficácia.

Almeida (2007) divide as armas biológicas em três gerações. A primeira geração é caracterizada pela fabricação rudimentar de instrumentos, seleção de poucos agentes infecciosos e baixa produção de munição, com aplicação precária e uso exclusivamente em sabotagens.

Os primeiros programas de guerra biológica ocorreram durante a Primeira Guerra Mundial, na Alemanha e na França, baseados nas descobertas da Microbiologia no século XIX, com o desenvolvimento dos métodos de isolamento, cultura e identificação de bactérias. Esses avanços possibilitaram o desenvolvimento de programas mais elaborados de armas biológicas com maior potencial de destruição, as quais posteriormente passaram a ser conhecidas como armas de destruição em massa (DAVIDSON, 2005).

Após a Primeira Guerra, os programas de guerra biológica existentes expandiram-se, enquanto outros foram iniciados, sendo construídas instalações para produção em larga escala de armas biológicas e sendo implementados testes de campo. $\mathrm{O}$ estudo dos agentes infecciosos possibilitou o desenvolvimento de novos armamentos e instrumentos de disseminação, surgindo a segunda geração de armas biológicas. Canadá, Polônia, Inglaterra, Rússia, Estados Unidos e Japão 
são países que tiveram seus programas de armas iniciados ou expandidos nesse período (CHRISTOPHER et al., 1997; SMART, 1997).

A descoberta do DNA em 1944 e de sua estrutura em 1953 permitiu o progresso da Genética. Desponta então a discussão no campo político estratégico para o desenvolvimento e uso de agentes infecciosos geneticamente modificados para uso bélico, a terceira geração de armas.

Observa-se também, na trajetória do desenvolvimento dos programas de armas biológicas, a construção de propostas para seu banimento. Entretanto, dois dos mais importantes tratados internacionais criados para esse fim, o Protocolo de Genebra (1925) e a Convenção para a Proibição de Armas Bacteriológicas (Biológicas) e Toxinas e sua Destruição (CPAB), não estabeleceram a realização de inspeções e o controle do desarmamento dos países membros, possibilitando a continuação e a criação de programas por diversos países.

A antiga União Soviética possuía um complexo industrial, o Biopreparat, criado em 1973 para desenvolver um programa de armas biológicas sob a cobertura da pesquisa biotecnológica civil e pacífica. O complexo continuou suas atividades mesmo após a CPAB. A ocorrência de uma epidemia de antraz na cidade russa de Sverdlovsk em 1979, infectando pessoas e animais através da inalação de esporos do Bacillus anthracis, dentro do raio de $50 \mathrm{~km}$ de distância do complexo comprovou a continuação do programa soviético (CHRISTOPHER et al., 1997; ROFFEY; TEGNELL; ELGH, 2002).

A crise verificada nos países do bloco soviético na década de 1980 favoreceu o fim da Guerra Fria, configurando novas correlações geopolíticas e destacando especialmente o potencial bélico dos países e seus projetos de hegemonia sobre regiōes consideradas estratégicas, em especial o Oriente Médio. Esse contexto potencializou um novo padrão de comportamento bélico, denominado "ameaças assimétricas". Os países alinhados com a liderança norte-americana verticalizaram cooperações visando à manutenção do controle sobre os grandes produtores de petróleo do Oriente Médio, região marcada historicamente por disputas políticas e territoriais. Com o atentado ao World Trade Center e a disseminação intencional de esporos de antraz através do sistema postal americano em 2001, o governo implementou o conceito doutrinário de combate preventivo (guerras preventivas) conhecido como "Doutrina Bush". Essa doutrina aprofundou uma série de medidas de caráter interno e externo, alertando para um inimigo fluido, o 
terrorismo. Sendo assim, o combate ao terror passou a compor o discurso político militar, que superou a lógica do discurso político legal, priorizando o combate ao bioterrorismo e alertando preventivamente para o que se chamou de "eixo do mal", composto pelo Irã, Iraque e Coreia do Norte. O termo "bioterrorismo" passou a circular com mais frequência na sociedade e na agenda política e militar dos países, sobretudo os ocidentais.

Embora a disseminação de agentes biológicos como instrumento agressor não seja um artifício novo na história, pode-se afirmar que o bioterrorismo atual está inserido em um mundo interligado, tendo, pois, uma dimensão mais complexa. As ações de bioterrorismo podem utilizar agentes capazes de promover epidemias, que certamente impactarão os sistemas de saúde dos países, em especial daqueles cujos sistemas já são sobrecarregados, caracterizados por uma infraestrutura deficitária. Considerando essa perspectiva, o bioterrorismo ultrapassa as áreas do campo militar (biodefesa) e torna-se um tema de relevância para os profissionais da área da saúde (biossegurança). Sublinha-se igualmente que é fundamental a atualização de informações científicas sobre os temas que integram biossegurança e as ameaças assimétricas, com a finalidade de melhorar a compreensão do bioterrorismo e sua correlação com a viabilidade do uso de artefatos de potencial risco biológico (INGLESBY et al., 2002; CARDOSO; CARDOSO, 2011).

Este estudo objetiva discutir a associação entre agentes biológicos e seu potencial de risco e a eficácia de estratégias fundamentadas no bioterrorismo, apontando para a importância das informaçóes como suporte para o mapeamento de locais ou situaçôes com potencial de ocorrência e para o planejamento das medidas de biossegurança.

\section{Metodologia}

O metodologia deste estudo baseou-se na leitura exploratória e seletiva, valorizando a revisão integrativa como facilitadora da construção de análises de contextos de risco relacionados ao tema. Estabeleceu-se como finalidade do estudo a proposição de conhecimentos voltados para o controle dos riscos relacionados às possibilidades de atentados bioterroristas no Brasil, indicando estratégias de avaliação de risco e de tomada de decisões.

O levantamento bibliográfico abrangeu um período de vinte anos (de 1990 a 2010), mediante busca eletrônica de artigos em português, inglês, ou espanhol na 
biblioteca virtual do Portal de Periódicos da Coordenação de Aperfeiçoamento de Pessoal de Nível Superior (Capes). Houve também um levantamento da legislação nacional e dos tratados internacionais que visam controlar o uso de agentes biológicos. $\mathrm{Na}$ Capes, foram consultadas as seguintes bases de dados: Institute for Scientific Information (ISI), Literatura Latino-Americana e do Caribe em Ciências da Saúde (LILACS), Scientific Electronic Library Online (SciELO) e Public Medline (PubMed).

Como localizadores dos artigos, foram utilizados os Descritores em Ciências da Saúde (DeCS) da Biblioteca Virtual em Saúde (BVS/BIREME) e suas combinações nas línguas portuguesa, espanhola e inglesa. Foram eles: "bioterrorismo", "guerra biológica”, "agentes biológicos", "exposição a agentes biológicos" e "biossegurança”. Foram excluídos da pesquisa resumos, notas prévias, conteúdos de caráter geral, estudos que não abordaram o tema discutido e artigos não disponibilizados na íntegra.

Foi feita a leitura integral dos artigos e a coleta de informações. A sistematização foi realizada por meio da análise dos textos selecionados, observando a valorização dos seguintes aspectos: qualificação dos periódicos; fator de impacto; abrangência das abordagens; citações de expertises; perspectiva plural das análises. Esses artigos permitiram também o entendimento de conceitos referentes ao tema, tais como guerra assimétrica e bioterrorismo. Tal procedimento possibilitou o diálogo com diferentes autores, contribuindo para a seleção das informações relevantes para compreensão do contexto de competências necessárias aos profissionais atuantes em situaçóes de primeira resposta na rede de serviços emergenciais de saúde. Essas competências devem incluir o rápido reconhecimento dos eventos de bioterrorismo e a identificação da doença através do diagnóstico clínico, permitindo o monitoramento e o tratamento de casos confirmados ou suspeitos de doenças infectocontagiosas de impacto e indicando as medidas de biossegurança adequadas à contenção dos riscos apresentados.

\section{Resultados e discussão}

O levantamento bibliográfico foi realizado em janeiro de 2013 e resultou em 414 artigos. 33 foram excluídos por serem duplicatas, resultando em 381 estudos. Considerando os critérios de inclusão e exclusão, foram selecionados 21 artigos completos para análise mais aprofundada (Tabela 1). Em seguida, 
foi construída uma tabela com as seguintes informações: autores, título do estudo, ano da publicação, tipo de estudo, conceito de bioterrorismo, emprego de agentes biológicos como armas. Os dados levantados foram agregados conforme a identificação de semelhanças e diferenças, compondo um achado interpretado e sustentado por outras literaturas pertinentes. Todos os estudos selecionados encontram-se referenciados neste estudo.

\section{Tabela 1. Detalhamento da pesquisa}

\begin{tabular}{|c|c|c|c|c|}
\hline \multirow{2}{*}{$\begin{array}{l}\text { Base de dados/ } \\
\text { Total de artigos } \\
\text { identificados }\end{array}$} & LILACS & SciELO & PubMed & ISI \\
\hline & 82 & 63 & 109 & 160 \\
\hline \multicolumn{4}{|c|}{ Resultado da busca } & 414 \\
\hline \multicolumn{4}{|c|}{ Número de duplicatas } & 33 \\
\hline \multicolumn{4}{|l|}{ Total de artigos } & 381 \\
\hline \multicolumn{4}{|c|}{ Número de artigos excluídos considerando critérios de inclusão e exclusão } & 360 \\
\hline \multicolumn{4}{|c|}{ Total de artigos selecionados } & 21 \\
\hline
\end{tabular}

\section{Bioterrorismo: conceito e motivações}

Define-se bioterrorismo como ameaças e ataques deliberados utilizando armas biológicas, visando criar pânico, insegurança, medo e traumas coletivos, gerando na sociedade apreensóes constantes e potencializando comportamentos considerados patológicos, manifestados socialmente (MORSE, 2003; ALMEIDA, 2007; RADOSAVLJEVIC; JAKOLJEVIC, 2007; CARDOSO; CARDOSO, 2011). O maior impacto do bioterrorismo recai sobre os sistemas de saúde pública, sobretudo os mais precários.

O Centers for Disease Control and Prevention (CDC) (2014) define arma biológica como qualquer material patogênico que possa impactar causando doença e morte em pessoas, animais ou plantas. Morse (2003) acrescenta a essa definição o propósito de causar também o terror, característica das guerras assimétricas, que se valem prioritariamente do elemento surpresa. 
Magalhães, citado por Pereira (2006), descreve bioterrorismo como uma estratégia que visa gerar danos e prejuízos de grande impacto, através do "uso intencional de microrganismos ou toxinas derivadas de organismos vivos, vírus ou príons, causando morte ou doença em humanos, animais ou plantas em comunidades civis". O bioterrorismo pode ocorrer por meio de fômites, animais, vetores, aerossóis contaminados por agentes infecciosos causadores de doenças emergentes, água e alimentos de origem animal ou vegetal contaminados.

Embora a definição de Magalhães seja mais abrangente, a inclusão do terror por Morse caracteriza bem a dimensão psicológica do bioterrorismo, uma das prioridades da ação terrorista.

Radosavljevic e Jakovljevic (2007) ressaltam que, apesar de uma ação de bioterrorismo resultar em doença e morte, seu objetivo principal é o desequilíbrio psicológico e emocional da população, com a disseminação de medo, pânico, ansiedade e insegurança, provocando a perda de confiança nas autoridades governamentais e prejuízos econômicos. Essas ações expõem os indivíduos à submissão pelo medo.

\section{Agentes biológicos: potencial de risco e eficácia como armas}

Existe uma gama de agentes biológicos que podem ser empregados em ações de bioterrorismo. Eles contêm informações genéticas e são capazes de autorreprodução ou de reprodução em um sistema biológico. Nessa categoria incluem-se "bactérias, fungos, vírus, clamídias, riquétsias, micoplasmas, príons, parasitos, linhagens celulares e outros organismos" (BRASIL, 2010, p.39), que podem causar doença ou morte e ser usados para contaminação não só dos seres humanos, animais e plantas, mas também de solo, alimentos ou água e para a deterioração de materiais (CANTERO; LANDEROS; CASTILLO, 2007).

O CDC/EUA classifica os agentes biológicos em três categorias (A, B e C), conforme critérios que determinam sua potencialidade para serem utilizados na forma de arma biológica (Figura 1). Dentre elas, destacam-se: infectividade, virulência, letalidade, patogenicidade, período de incubação, transmissibilidade e estabilidade (KHAN; MORSE; LILLIBRIDGE, 2000;). 


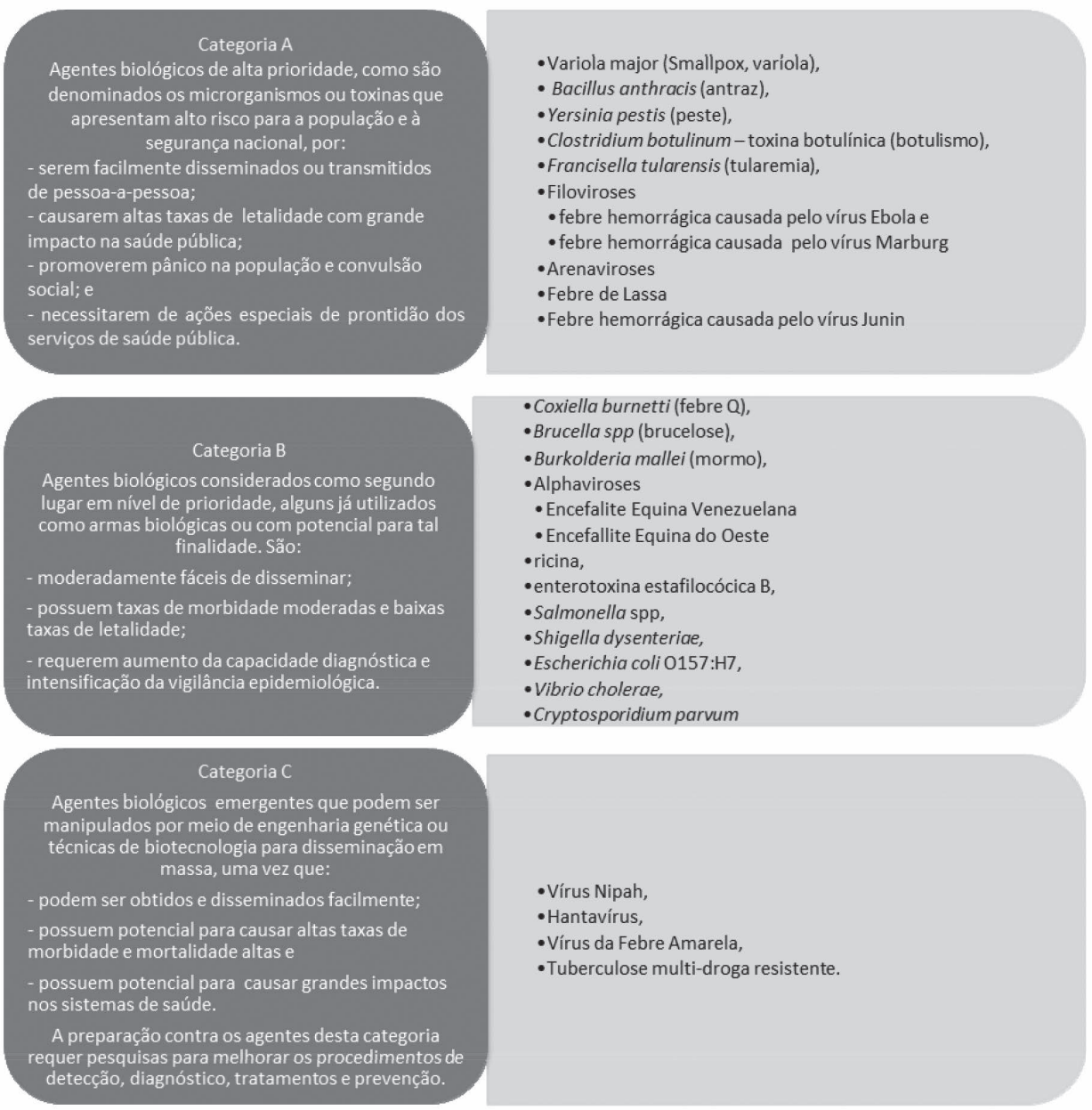

Fonte: CDC (2014)

Diversos agentes biológicos foram estudados com o objetivo de verificar seu potencial de uso como agente de guerra biológica, porém poucos apresentaram características satisfatórias. Mesmo estes precisam ser transformados em armas, processo no qual são exigidos diversos requisitos. $\mathrm{O}$ agente deve ser suficientemente estável à degradação durante a manipulação, o armazenamento e os processos de transferência de energia implicados na maioria dos cenários de disseminação. Uma vez liberado, o agente deve manter-se em doses infectantes em uma área 
previsível. Esses fatores demonstram a dificuldade e até mesmo a inviabilidade da utilização desse tipo de armamento.

Os sistemas de saúde pública dos países e os profissionais de saúde devem estar preparados para lidar com os surtos ocasionados pelos mais diversos tipos de agentes biológicos, incluindo os exóticos.

Nas últimas três décadas, houve diversos casos ocasionados pelo uso deliberado de um agente biológico. Três eventos merecem destaque: o surto de salmonelose, em 1984, que acometeu 751 pessoas, com 45 hospitalizações, por contaminação de um buffet de saladas de restaurantes, causado por uma seita religiosa indiana e comandado pelo guru Bhagwan Shree Rajneesh (RADOSAVLJEVIC; JAKOLJEVIC, 2007); a disseminação mal sucedida de esporos de antraz em 1993, no Japão, por membros da seita religiosa da Verdade Suprema (Aum Shinrikyo) (TAKAHASHI et al., 2004); e a disseminação de esporos de antraz por meio do sistema postal americano, após o ataque terrorista de 2001, que detonou 23 casos. Esses fatos e suas consequências mostram que, quanto mais bem preparado o sistema de saúde local estiver, menores serão as consequências do ataque, além de trazerem um questionamento: onde a capacidade de responder a um surto deliberado diverge da resposta a um evento natural ou acidental? Um sistema de saúde pública eficiente deveria gerir um surto, independente de suas origens.

$\mathrm{Na}$ prática, a divergência ocorre entre os elementos técnico-científicos para responder às questôes relacionadas aos ilícitos penais (conhecimentos da ciência forense) e à preparação para a investigação epidemiológica não prevista, a qual requer planejamento de contingência, treinamento e conhecimento para criar e manter vínculos interinstitucionais entre a aplicação da lei e a saúde pública (ISLA, 2009) (Figura 2). As respostas do sistema de saúde pública para ambos os surtos devem ser praticamente idênticas. No entanto, no plano político, as motivaçôes para o desenvolvimento de capacidades são mundos separados. Para o monitoramento, detecção e resposta de doenças infecciosas, falta o planejamento de segurança. Contudo, atualmente já há uma sensibilização política, dentro das agendas de segurança nacionais e internacionais, de que é necessário desenvolver a capacidade da saúde pública para tornar tais monitoramentos mais eficientes, uma vez que o fortalecimento da saúde pública não só irá contribuir para a prevenção e tratamento das doenças, mas também irá fornecer a base para uma efetiva defesa global contra o bioterrorismo (UN, 2004). 
Figura 2. Sobreposição das ações da saúde pública e das ações relacionadas a um surto deliberado de agentes biológicos.

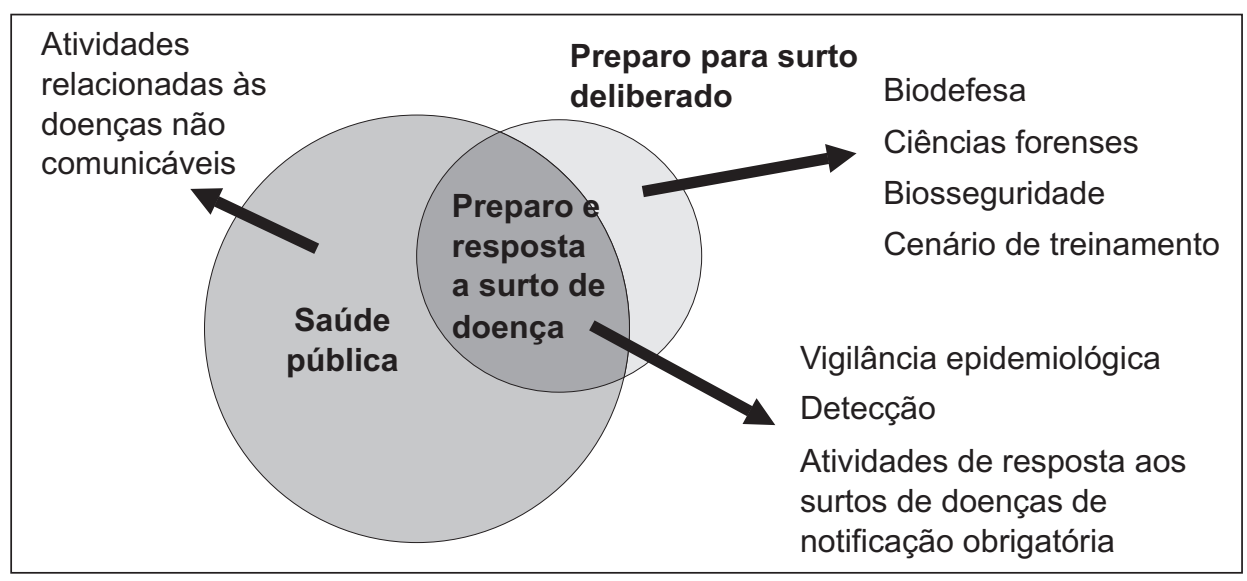

Fonte: adaptado de Isla (2009)

Como os surtos de origem natural e os surtos de origem intencional podem ser provocados pelos mesmos agentes biológicos, existem alguns aspectos que podem auxiliar a diferenciar da origem da epidemia (MORSE, 2003):

- Grande número de vítimas sem nexo causal;

- Taxas de morbidade e mortalidade mais altas do que o esperado;

- Surgimento de uma doença incomum em uma determinada região geográfica. Esse aspecto está principalmente relacionado a uma doença que requer um vetor competente para sua disseminação e este não é identificado. Nesse caso, suspeita-se da possibilidade de disseminação de um agente infeccioso na forma de aerossol;

- Progressão da epidemia no tempo com características de uma exposição maciça. Em um evento intencional com dispersão do agente por meio de aerossóis, a curva epidêmica tem uma característica bem definida, podendo-se observar um aumento expressivo no número de doentes ou mortos, um ápice e, em seguida, uma regressão acentuada;

- Múltiplos surtos epidêmicos;

- Baixas taxas de ataque de uma doença em indivíduos protegidos através da vacinação ou do uso de trajes de proteção;

- Presença de animais mortos ou de vegetação alterada; 
- Disseminação invertida. A característica típica das zoonoses é o agente biológico atingir inicialmente a população animal e os casos humanos surgirem a seguir. Quando o contrário ocorre, ou ambos adoecem juntos, o episódio deve ser objeto de investigação, considerando-se a possibilidade de uma epidemia intencional;

- Manifestação clínica não usual da doença. Exemplifica-se com a epidemia de antraz na Rússia, em 1979, com o aparecimento de 66 casos da infecção na forma respiratória, uma vez que $95 \%$ dos casos de infecção pelo $B$. anthracis ocorrem na forma cutânea. Esse fato sinaliza a possibilidade de um evento não natural;

- Avaliação das condições meteorológicas e das características geográficas da região. A disseminação da doença é provável dada a localidade?

- Evidências diretas, tais como existência de cartas contendo pó branco, placas de Petri com culturas biológicas, equipamentos de dispersão de agentes biológicos como pulverizadores, suspensões líquidas de aspecto suspeito, dentre outros.

É importante esclarecer que a origem da epidemia, natural, acidental ou deliberada, não irá determinar de forma significativa uma variação nos aspectos fundamentais da investigação e do gerenciamento dos surtos de doenças infecciosas. Entretanto, nos casos de suspeita ou confirmação da disseminação intencional de agentes biológicos, além dos profissionais de saúde, outros profissionais devem ser envolvidos, como os responsáveis pela segurança nacional e pela ordem pública. Procedimentos de segurança devem ser tomados em relação às amostras coletadas, seu transporte e armazenamento, à identificação dos responsáveis e às demais medidas cabíveis.

O conceito de biosseguridade emergiu das preocupações com a logística de defesa nacional e a política de monitoramento das armas de destruição em massa, sendo utilizada também como argumento para intençôes de interesses geopolíticos dos países hegemônicos. Destaca-se que as ações baseadas na biosseguridade devem estar integradas aos procedimentos de biossegurança, tendo como perspectiva a prevenção, detecção e mitigação das consequências do uso de armas biológicas, incluindo investimentos em tecnologias voltadas para a saúde pública e abrangendo os campos da medicina veterinária e da agricultura (CARDOSO et al., 2008). 


\section{Saúde pública, convenções internacionais e a legislação nacional}

Apesar das armas biológicas serem utilizadas desde a antiguidade, os agentes biológicos nunca foram empregados em larga escala. Contudo, durante a Segunda Guerra Mundial, os japoneses, em um complexo denominado Unidade 731, na Manchúria, desenvolveram um programa de armas biológicas, onde foram produzidos B. anthracis, Neisseria meningitidis, Shigella spp., Vibrio cholerae e Yersinia pestis. Diversas experiências em seres humanos e ataques contra a população civil foram realizados, estimando-se um número de vítimas entre 5.000 e 10.000 (CHRISTOPHER et al., 1997; BHALLA; WARKEIT, 2004).

Ainda que não tenha sido motivada por questôes de saúde pública, a comunidade internacional chegou ao acordo sobre a necessidade de banir o emprego de tais tipos de armas. O Protocolo de Genebra e a CPAB estão entre os principais tratados estabelecidos com esse fim.

O Protocolo de Genebra, em 1925, determinou a proibição do emprego de armas químicas e bacteriológicas na guerra. Os vírus ainda não estavam incluídos, uma vez que nesse período ainda não os diferenciavam de bactérias. Porém, tratava-se da proibição apenas do uso desse tipo de arma, mas não da pesquisa básica, desenvolvimento, produção, posse, armazenamento, entre outras atividades relacionadas. No Brasil, o texto do Protocolo só foi aprovado pelo Decreto Legislativo no 39 (1970a) e promulgado pelo Decreto no 67.200 (1970b).

A Convenção para a Proibição de Armas Bacteriológicas (Biológicas) e Toxinas e sua Destruição (CPAB), elaborada em 1972, complementou a exclusão das armas biológicas, proibindo seu desenvolvimento, sua produção, estocagem, aquisição, conservação e transferência, além de exigir sua destruição. A CPAB entrou em vigor em março de 1975 e foi aprovada no Brasil pelo Decreto Legislativo no 89 (1972) e promulgada pelo Decreto no 77.374 (1976).

No Brasil, os agentes biológicos com risco potencial de utilização em bioterrorismo podem ser classificados como armas de destruição em massa $(\mathrm{ADM})$ e, portanto, foram considerados bens sensíveis. Os bens sensíveis são definidos pela Lei no 9.112 (1995) como sendo de uso na área nuclear, química, biológica e missilística, incluindo os bens de uso duplo previstos nas convençôes internacionais citadas anteriormente. Entendem-se por bens de uso duplo, ou uso dual, aqueles que podem ser empregados para finalidades bélicas, mesmo que tenham sido desenvolvidos para aplicações civis. Esses bens e serviços são 
classificados, quanto às suas naturezas, de acordo com o tratamento específico que lhes é dado no plano internacional (BRASIL, 1995; 2014a). A Lei no 9.112 cria, no âmbito da Presidência da República, a Comissão Interministerial de Controle de Exportação de Bens Sensíveis (CIBES), integrada por representantes dos órgãos federais envolvidos no processo de exportação dos bens sensíveis, e institui o Ministério da Ciência e Tecnologia como órgão coordenador.

A secretaria executiva da CIBES é a Coordenação-Geral de Bens Sensíveis (CGBE), e é composta pelos Ministérios da Justiça, da Defesa, do Desenvolvimento, Indústria e Comércio Exterior e da Fazenda.

A CGBE tem como principais atribuições o acompanhamento da implementação da política de controle de exportação de bens sensíveis e serviços diretamente vinculados a tais bens e o acompanhamento das convenções ou tratados internacionais nas áreas do desarmamento e da não proliferação de armas de destruição em massa, dos quais o Brasil faz parte (BRASIL, 2014b). A CGBE controla os pesquisadores que manipulam agentes biológicos com características de uso dual em pesquisas e com finalidades profiláticas estabelecidos na Resolução CIBES no 13, de 2010. Essa resolução inclui não apenas agentes com características duais, mas também equipamentos que possam ser utilizados para a produção, armazenamento e disseminação.

Pesquisas que utilizam agentes biológicos altamente patogênicos em laboratórios de nível de biossegurança 3 e 4 são importantes para a saúde pública, uma vez que possibilitam o desenvolvimento de novos métodos de diagnóstico, vacinas e terapias para evitar epidemias.

Historicamente, o número de vítimas conhecidas e de mortes causadas pelo uso intencional de agentes biológicos é consideravelmente menor, em comparação com os mesmos efeitos causados por infecções naturais. A partir desse entendimento, o Brasil vem desenvolvendo uma estratégia de vigilância, de base epidemiológica, laboratorial e clínica, implantada pelo Ministério da Saúde (MS) em 1995, com o Projeto Brasileiro de Capacitação Científica e Tecnológica em Doenças Infecciosas Emergentes e Reemergentes. O MS compreendia como fator essencial no avanço das instituiçōes brasileiras na área de vigilância em saúde as questôes de biossegurança, no que se referisse tanto à adequação de infraestrutura das instituições quanto, e, principalmente, à mudança de comportamento. O MS entendeu que a biossegurança transcende 
os aspectos da manipulação genética e suas implicações éticas, restritas a um universo de instituições altamente especializadas e, assim, priorizou investimentos nos laboratórios constituintes da Rede Nacional de Laboratórios de Saúde Pública. Como estratégias gerais, definiram-se três áreas de ação: educação continuada; elaboração de normas referentes à biossegurança e reforma ou construção de áreas laboratoriais de contenção de nível de biossegurança 3 (NB-3). Foram capacitados mais de 4.000 profissionais da Rede e, a partir de 2005, iniciou-se a implantação de 12 áreas laboratoriais NB-3, fortalecendo a vigilância epidemiológica, em especial para doenças de transmissão aérea, provocadas por agentes pertencentes à classe de risco 3.

Os laboratórios são classificados em níveis de biossegurança (NB1, NB2, NB3 ou NB4) de acordo com a avaliação de risco, que considera, entre outros fatores, o agente biológico a ser manipulado e o ensaio a ser desenvolvido. A avaliação baseia-se em critérios como patogenicidade, virulência, modo de transmissão, endemicidade, resistência a drogas, possibilidade da atividade de gerar aerossóis, volume, concentração e disponibilidade de profilaxia e/ou tratamento eficazes, dentre outros.

Os níveis e suas exigências são crescentes no grau de contenção e complexidade no nível de proteção. Dessa forma, o NB-1 é um laboratório básico, onde são manipulados agentes biológicos de baixo risco, e o NB-4 é o nível de maior contenção, onde se manipulam agentes extremamente perigosos. $\mathrm{O}$ Brasil até o momento não possui nenhum laboratório NB-4.

\section{Brasil e a possibilidade de um evento deliberado}

Apesar de o Brasil ser considerado um país pacífico, o risco de bioterrorismo atualmente é uma ameaça real e não deve ser desconsiderado. O antropólogo Mércio Gomes, no livro Os indios e o Brasil (1988) relata que a primeira utilização deliberada do vírus da varíola no Brasil ocorreu entre os índios. Aconteceu em Caxias, no Maranhão, em 1815, durante uma visita dos índios Canelas Finas, quando as autoridades locais lhes presentearam com brindes e roupas previamente contaminadas por doentes.

Há também a suspeita da utilização, por meio de técnicas rudimentares, de agentes etiológicos de doenças como sarampo, varíola, catapora, tuberculose e influenza contra diversas tribos indígenas que habitavam áreas de extração de 
borracha, no estado de Mato Grosso, entre 1957 e 1963 (DAVIS, 1978; NOJI, 2001; TAKAHASHI et al., 2004).

Davis (1978), estudando o desenvolvimento e os índios no Brasil, ao pesquisar os arquivos do Ministério do Interior, relatou a introdução consciente da tuberculose entre as tribos do Norte da Bacia Amazônica entre 1964 e 1965. Outro episódio suspeito de ser um ato de bioterrorismo é a introdução da doença conhecida por "vassoura-de-bruxa", que devastou as plantações de cacau no sul da Bahia, no período de 1980 a 1990 (PEREIRA, 2006).

Todos esses relatos sobre suspeitas de eventos de bioterrorismo no Brasil foram pouco estudados e demonstram que há necessidade de estabelecer-se um sistema de segurança e controle a fim de proteger a população de um ataque desse tipo.

Outro ponto importante a ser considerado é o risco de ocorrência de um atentado de bioterrorismo devido à existência de alvos compensatórios. Podese dizer que atualmente o Brasil estará mais exposto a esse tipo de atentado ao sediar eventos internacionais como a Copa das Confederaçóes (2013), a Copa do Mundo (2014) e as Olimpíadas (2016). Nesses eventos, em que estão presentes pessoas de diferentes nacionalidades e religiōes, são necessárias medidas de segurança como a detecção de aerossóis de agentes biológicos e sua identificação em tempo real, para que sejam implementadas açôes nos aeroportos, estádios e outros locais de grande concentração populacional.

\section{Medidas de biossegurança para resposta aos atentados de bioterrorismo}

É imprescindível estabelecer o diagnóstico clínico-laboratorial e uma rede ágil de informações epidemiológicas, a fim de minimizar os efeitos sobre a população atingida e o consequente impacto sobre os serviços de saúde, pelo aumento inesperado do número de pacientes, que venha a sobrepujar os recursos médicos disponíveis, inclusive os estoques de medicamentos e vacinas.

Atualmente, o número de leitos e recursos assistenciais de saúde não é suficiente para atender as vítimas de um atentado bioterrorista. Além disso, os profissionais da saúde necessitarão de proteção adicional, devido ao alto risco de contaminação inerente às situações dessa natureza. Nesse contexto, a biossegurança surge para atuar no controle dos riscos, de forma a preservar a vida, através de um conjunto de ações destinadas a prevenir, controlar, reduzir ou eliminar riscos inerentes às atividades que possam comprometer a saúde pública ou o ambiente. 
Os agentes biológicos foram divididos em quatro classes de risco, a fim de facilitar a sua manipulação seguindo as medidas de biossegurança (BRASIL, 2010). Ressalta-se que a maioria dos agentes biológicos com potencial de risco para emprego em bioterrorismo se enquadram nas classes de risco 3 e 4.

Os agentes da classe de risco 1 têm baixa probabilidade de causar doenças em pessoas ou animais adultos sadios, e exemplificam-se com o Lactobacillus sp. e o Bacillus subtilis (BRASIL, 2010). Já na classe 2, representada pelo Schistosoma mansoni, Trypanossoma cruzi e vírus da Hepatite B, C e E, o risco individual é moderado e o risco para a comunidade é limitado. Seus agentes podem provocar infecçôes, porém existem medidas terapêuticas e profiláticas eficazes, sendo o risco de propagação limitado (BRASIL, 2010). Os agentes da classe 3 têm capacidade de transmissão aérea, causando patologias que podem se propagar de pessoa para pessoa (ou entre animais) e são potencialmente letais. No entanto, usualmente existem medidas de tratamento e/ou de prevenção. Exemplificam-se com Bacillus anthracis, Coccidioides immitis e hantavírus (BRASIL, 2010).

$\mathrm{O}$ risco individual e para a comunidade é elevado na classe 4. Nela estão os agentes com grande poder de transmissibilidade por via respiratória ou de transmissão desconhecida, sendo altamente patogênicos e com alta capacidade de disseminação. Até o momento não há medidas profiláticas ou terapêuticas eficazes contra infecçôes ocasionadas por esses agentes. Nessa classe incluem-se principalmente vírus como o Ebola e o Sabiá (BRASIL, 2010).

As medidas de proteção da população em geral, dos profissionais de saúde, das equipes de segurança e de todo o pessoal envolvido em um ataque variam segundo o risco ou seu uso confirmado e também segundo a exposição confirmada sem sintomas ou na vigência de sinais e sintomas. Dessa forma, é importante a capacitação dos profissionais que realizarão o atendimento hospitalar e de todos aqueles envolvidos no atendimento pré-hospitalar. Esses trabalhadores, antes da exposição, necessitam estar vacinados e ser tratados profilaticamente com antibióticos para prevenir o aparecimento da doença. Esse é provavelmente o melhor mecanismo de proteção contra a maioria dos agentes biológicos conhecidos.

Após um atentado de bioterrorismo, deve-se isolar o cenário onde o atentado ocorreu, iniciar os processos de descontaminação, estabelecer quarentena e realizar 
uma avaliação médica de emergência para proceder à quimioprofilaxia adequada.

A simples remoção das roupas elimina a maior parte da contaminação. Depois, recomenda-se um banho com água e sabão. Assim, espera-se remover 99\% dos organismos da pele do paciente (BRASIL, 2013).

A finalidade da descontaminação depois da exposição aos aerossóis dispersados pela arma biológica é remover ou diminuir a contaminação do corpo ou da roupa do paciente, prevenindo a reaerossolização e exposição adicional das vias respiratórias.

A descontaminação da pele com uma solução de hipoclorito de sódio, como um método de controle de infecção, não é recomendada. Apesar de ser eficaz na descontaminação de superfícies, materiais e equipamentos, para alguns tipos de agentes biológicos, sua eficácia na desinfecção em casos de bioterrorismo é questionável e não recomendada (RUTALA; WEBER, 1997; HENDERSON, 1999; KEIM; KAUFMANN, 1999; INGLESBY et al., 1999; ENGLISH et al., 1999).

Outro ponto importante é o isolamento e o estabelecimento de medidas ou precauções para a prevenção e o controle de infecçôes, seguindo os requisitos de biossegurança preconizados. Portanto, o objetivo básico de um sistema de precauções e isolamento é a prevenção da transmissão de agentes patogênicos.

O primeiro requisito, e mais importante, é a utilização das precauções padrão, que devem ser adotadas durante o atendimento pré-hospitalar e o tratamento de pacientes hospitalizados, independente do diagnóstico definido ou presumido de infecção. Essas precauçōes reduzem o risco da transmissão dos agentes biológicos a partir de fontes, conhecidas ou desconhecidas, de infecção nos hospitais. Consistem em:

- usar luvas ao manipular material potencialmente contaminado e lavar as mãos após a manipulação;

- usar roupas protetoras, máscara de proteção respiratória e óculos de proteção ou protetor de face para proteger as membranas mucosas dos olhos, nariz e boca durante os procedimentos e as atividades de cuidado com o paciente onde haja probabilidade de produção de gotículas;

- ter cuidado ao manipular equipamentos contaminados com material/secreções do paciente, de forma a prevenir a transmissão secundária;

- descontaminar quimicamente superfícies; 
- seguir as recomendações para a manipulação de agentes de transmissão sanguínea para diminuir o risco de contaminação dos pacientes durante a manipulação de equipamentos; e

- acomodar os pacientes que apresentem alto risco de contaminação ambiental em quarto de isolamento (KEIM; KAUFMANN, 1999; BRASIL, 2000; NAEMT, 2010).

Outro requisito importante é a adoção das precauções para controle de infecção baseadas no tipo de transmissão. Essas medidas são específicas e devem ser seguidas para o tratamento dos pacientes confirmados ou suspeitos de estarem infectados com patógenos de importância epidemiológica que possam ser transmitidos pela via aérea através de gotículas ou pelo contato com pele seca e superfícies contaminadas. Essas precauções dependem, portanto, da via de transmissão (KEIM; KAUFMANN, 1999; BRASIL, 2000; NAEMT, 2010).

No entanto, ressalta-se que os agentes biológicos de ameaça não são facilmente transmitidos de pessoa para pessoa. Das doenças de interesse para o bioterrorismo, esse tipo de transmissão só é possível com a varíola e a peste pneumônica. Para o manejo de pacientes infectados com o vírus da varíola, é exigido o cumprimento das precauções por via aérea e de contato, e para os infectados com a peste pneumônica, as precauções por gotículas (KEIM; KAUFMANN, 1999; BRASIL, 2000; NAEMT, 2010).

As precauções aéreas são exigidas quando a transmissão se faz por pequenas partículas $(\leq 5 \mu \mathrm{m})$ que permanecem suspensas no ar durante longos períodos e podem ser disseminadas à distância através de correntes de ar. A vítima deve ser acomodada em um quarto com pressão negativa, com seis trocas de ar/hora; o ar não pode ser recirculado e o ar de exaustão deve passar por filtros de alta eficiência, do tipo HEPA. Todos os profissionais de assistência devem utilizar máscaras de proteção respiratória de alta eficiência (N95) e, caso seja necessário o transporte do paciente, este deve usar uma máscara cirúrgica (KEIM; KAUFMANN, 1999; BRASIL, 2000; NAEMT, 2010).

Quando a transmissão se faz através de gotículas respiratórias expelidas a curtas distâncias $(<1 \mathrm{~m})$ por tosse, espirro, fala ou procedimentos como aspiração de secreções ou broncoscopias, devem ser cumpridas as precauções para gotículas. Essas partículas, por serem pesadas, não permanecem suspensas no ar; dessa forma, não 
há necessidade de sistemas de filtragem de ar ambiental. A vítima deve ser internada preferencialmente em quarto privativo ou, quando não for possível, em quarto com pessoas que tenham a mesma infecção. Caso não haja essa possibilidade, deve-se manter uma distância mínima de 1,5 m entre os leitos. Os profissionais devem cumprir as precauções padrão, além de utilizar máscaras de proteção respiratória, óculos de proteção e protetor de face quando estiverem a uma distância de $80 \mathrm{~cm}$ do paciente. Deve-se também evitar ao máximo o transporte do paciente (KEIM; KAUFMANN, 1999; BRASIL, 2000; NAEMT, 2010).

Contudo, o contato é o modo mais comum de transmissão de infecçôes. As precauções devem ser diferenciadas quando a transmissão do agente se faz através do contato direto, isto é, quando há transferência do agente resultante do contato físico direto entre o paciente e um hospedeiro susceptível; ou por contato indireto, quando a transferência se faz de forma passiva, através de superfícies ambientais e qualquer objeto intermediário, por exemplo, mãos ou objetos contaminados. A vítima deve ser acomodada em quarto privativo ou com grupos de pessoas com o mesmo tipo de infecção. Os profissionais devem, além de cumprir com as precauções padrão, usar luvas e roupas protetoras. Os equipamentos utilizados no cuidado com o paciente devem ser preferencialmente exclusivos, e limpá-los e desinfetá-los caso haja compartilhamento de material entre pacientes (KEIM; KAUFMANN, 1999; BRASIL, 2000; NAEMT, 2010).

A Tabela 2 lista as precauções baseadas na transmissão.

Tabela 2. Resumo das Precauções para Controle de Infecção de Doenças Causadas por Agentes Biológicos com Potencial de Bioterrorismo

\begin{tabular}{|l|c|}
\hline \multicolumn{1}{|c|}{ Doença } & Tipo de Precaução \\
\hline Febre de Lassa & Padrão, Aérea, Contato \\
\hline Ebola & Padrão, Aérea, Contato \\
\hline Vírus Marburg & Padrão, Aérea, Contato \\
\hline Varíola & Padrão, Aérea, Contato \\
\hline Antraz & Padrão, Aérea, Contato \\
\hline Varíola das aves (Chickenpox) & Padrão, Aérea, Contato \\
\hline Peste pneumônica & Padrão e Gotículas \\
\hline Pneumonia por Mycoplasma & Padrão e Gotículas \\
\hline
\end{tabular}




\begin{tabular}{|l|l|}
\hline \multicolumn{1}{|c|}{ Doença } & \multicolumn{1}{c|}{ Tipo de Precaução } \\
\hline Antraz pulmonar ou inalatório & Padrão \\
\hline Encefalite Equina Venezuelana & Padrão \\
\hline Botulismo & Padrão \\
\hline Brucelose & Padrão \\
\hline Cólera & Padrão \\
\hline Febre Q & Padrão \\
\hline Tularemia pulmonar & Padrão \\
\hline Pneumonia estreptocócica & Padrão \\
\hline
\end{tabular}

Fonte: Keim e Kaufmann (1999), Garner (1996), Brasil (2000), CDC (2007), NAEMT (2010).

\section{Conclusão}

O final da Guerra Fria registrou a elaboração de um padrão de comportamento bélico mundial, as ameaças assimétricas. A fim de combatê-las, especialmente após o evento de 2001, o governo norte-americano implementou um novo conceito doutrinário de combate preventivo de ameaças, a "Doutrina Bush". As consequências dessa doutrina, que exacerba o discurso político militar em vez do político legal, são o aumento da guerra assimétrica na forma de ameaça terrorista, e, por conseguinte, o bioterrorismo.

O bioterrorismo é uma ameaça real em todo o mundo, inclusive no Brasil, que está inserido no processo de globalização mundial e com previsão de sediar eventos esportivos internacionais, com pessoas de diversos países, as quais podem ser consideradas alvos compensatórios para atentados terroristas.

Com isso, o combate ao bioterrorismo deve ser realizado através da divulgação de informações, da disseminação do conhecimento e da capacitação dos profissionais responsáveis por atuar em situações de primeira resposta, a fim possibilitar o reconhecimento de um evento de bioterrorismo e identificar a doença através de diagnóstico clínico preciso, permitindo o tratamento de forma eficaz.

É clara a importância da biossegurança na correlação com as ações de resposta ao bioterrorismo, dada por medidas ou precauções, uso de equipamentos de proteção individual e coletivos, contenção de áreas, descontaminação, avaliação de risco, entre outras. 
Uma vez que os patógenos com características de uso dual fazem parte tanto

de listas de agentes pertencentes aos programas de guerra biológica quanto das listas de arsenais de armas de grupos terroristas, deve-se considerar a necessidade de preparar o país para lidar com as consequências de tais eventos, nos quais o pânico costuma ser tão ou mais efetivo que o agente disseminado.

Torna-se, portanto, necessária a capacitação dos profissionais para a identificação precoce dos sintomas, das vulnerabilidades sociais e ambientais e da susceptibilidade para cada doença, a fim de prestar esclarecimentos à população em geral sobre sintomas e medidas de controle, envolvendo cada vez mais as temáticas das doenças infecciosas, a biossegurança e a segurança biológica, promovendo não apenas a proteção dos profissionais envolvidos, mas também contendo a propagação da doença e a contaminação ambiental. Deve ser uma preocupação de todos os países assegurar uma resposta estratégica de prevenção e contenção em resposta às ações de bioterrorismo, com o reforço da vigilância militar e o surgimento de um sistema de comunicação entre as agências de saúde e defesa, assim como a criação de laboratórios forenses e centros de pesquisas biológicas, a produção de vacinas e de kits diagnósticos, a preparação de profissionais treinados prontos a lidar com as consequências de um ataque e a discussão de planos e protocolos de ações e medidas educativas. ${ }^{1}$

\section{Referências}

ALMEIDA, M.E. O desenvolvimento biológico em conexão com a guerra. Physis, Rio de Janeiro, v.17, n.3, p.545-564, 2007.

BHALLA, D.K.; WARKEIT, D.B. Biological agents with potential for misuse: a historical perspective and defensive measures. Toxicol Appl Pharmacol, New York, v.199, n.1, p. 71-84, 2004.

BRASIL. Decreto Legislativo n039, de 1 de julho de 1970(a). Diário Oficial [da] República Federativa do Brasil, Brasília, DF, Seção 1, 2 jul. 1970, p.4865.

. Decreto $\mathrm{n}^{0}$ 67.200, de 15 de setembro de 1970(b). Promulga o Protocolo de Genebra. Diário Oficial [da] República Federativa do Brasil, Brasília, DF, Seção 1, 17 set. 1970, p.8089.

Decreto Legislativo n ${ }^{0} 89$, de 05 de dezembro de 1972. Diário Oficial [da] República Federativa do Brasil, Brasília, DF, Seção 1, 6 dez. 1972, p.10893.

. Decreto $\mathrm{n}^{0} 77.374$, de 01 de abril de 1976. Diário Oficial [da] República Federativa do Brasil, Brasília, DF, Seção 1, 2 abr. 1976, p.4284. 

Ministério da Ciência e Tecnologia. Lei no9.112, de 10 de Outubro de 1995. Diário Oficial [da] República Federativa do Brasil, Brasília, DF, Seção 1, 11 out. 1995, p.16056. - Ministério da Ciência e Tecnologia. Coordenação-Geral de Bens Sensíveis. Disponível em: <http://www.mct.gov.br/index.php/content/view/41958.html> Acesso em: 23 jul 2014a.

- Ministério da Ciência e Tecnologia. Coordenação-Geral de Bens Sensíveis. Disponível em: <http://www.mct.gov.br/index.php/content/view/68702.html> Acesso em: 23 jul 2014b.

- Ministério da Ciência e Tecnologia. Resolução no13, de 10 de março de 2010. Diário Oficial [da] República Federativa do Brasil, Brasília, DF, Seção 1, 18 mar. 2010, p.00007.

Ministério da Saúde. Agência Nacional de Vigilância Sanitária. Medidas de Prevenção de Infeç̧ão Relacionada à Assistência à Saúde. Brasília: MS, 2013.

- Ministério da Saúde. Agência Nacional de Vigilância Sanitária. Curso Básico de Controle de Infecção Hospitalar. Caderno C. Métodos de Proteção Anti-Infecciosa. Brasília: MS, 2000.

Ministério da Saúde. Classificação de Risco dos Agentes Biológicos. Brasília: MS, 2010. CANTERO, N.; LANDEROS, J.P.; CASTILLO, J.L. Bacterias y su uso como armas biológicas. Rev. latinoam. actual. Bioméd, Concepción, v.1, n.1, p.10-16, 2007.

CARDOSO, D.R.; CARDOSO, T.A.O. Bioterrorismo: dados de uma história recente de riscos e incertezas. Ciênc Saúde Coletiva, Rio de Janeiro, v.16, n.1, p.821-830, 2011.

CARDOSO, T.A.O. et al. Biosseguridade e Biossegurança: aplicabilidades da segurança biológica. Interciência, Caracas, v.33, n.8, p.561-568, 2008.

CENTERS FOR DISEASE CONTROL AND PREVENTION. Bioterrorism Overview. Disponível em: http://emergency.cdc.gov/bioterrorism/overview.asp> Acesso em: 27 jul. 2014.

. Guideline for Isolation Precautions: preventing transmission of infectious agents in healthcare settings. Atlanta: CDC, 2007.

CHRISTOPHER, G.W. et al. Biological warfare: a historical perspective. JAMA, Chicago, v.278, n.5, p.412-417, 1997.

DAVIDSON, N. The Role of Scientific Discovery in the Establishment of the First Biological Weapons. Programmes Bradford Science and Technology Report No. 5. 2005.

DAVIS, S. Vitimas do Milagre. O desenvolvimento e os índios no Brasil. Rio de Janeiro: Zahar, 1978.

ENGLISH, J.F. et al. Bioterrorism Readiness Plan: a Template for Healthcare Facilities. Atlanta: CDC, 1999. 
GARNER, J.S. Guideline for isolation procedures in hospitals. The Hospital Infection

Control Practices Advisory Committee. Infect Control Hosp Epidemiol, Chicago, v.17, n.1, p.53-80, 1996.

GOMES, M.P. Os Índios e o Brasil: ensaio sobre um holocausto e sobre uma nova possibilidade de convivência. Petrópolis: Vozes, 1988.

HENDERSON, D.A. The looming threat of bioterrorism. Science, New York, v.283, n.5406, p.1279-1282, 1999.

INGLESBY, T.V. et al: Anthrax as a biological weapon: medical and public health management. JAMA, Chicago, v.281, n.18, p.1735-1745, 1999.

INGLESBY, T.V. et al. Anthrax as a biological weapon, 2002: update recommendations for management. JAMA, Chicago, v. 287, n.17, p. 2236-2252, 2002.

ISLA, N. Biological Weapons as a Public Health Issue. In: MACLAUGHLIN, K.; NIXDORFF, K. (Ed.). BWPP Biological Weapons Reader. Geneva: Bioweapons Prevention Project, 2009. p.53-58.

KEIM, M.; KAUFMANN, A.F. Principles for Emergency Response to Bioterrorism. Ann Emerg Med, St. Louis, v.34, n.2, p.177-182, 1999.

KHAN, A.S.; MORSE, S.; LILLIBRIDGE, S. Public-health preparedness for biological terrorism in the USA. Lancet, London, v.356, n. 9236, p .1179-1182, 2000.

MORSE, S.S. Biological and chemical terrorism. Technology in Society, Amsterdan, v.25, n.4, p. 557-563, 2003.

NATIONAL ASSOCIATION OF EMERGENCY MEDICAL TECHNICIANS. Prehospital Trauma Life Support. Oxford: Mosby JEMS, 2010.

NOJI, E.K. Bioterrorism: a 'new' global environmental health threat. Glob Chang Human Health, Amsterdan, v.2, n.1, p.2-10, 2001.

PEREIRA, S. Pragas e tráfico de material biológico em debate. Revista do Conselho Regional de Engenharia, Arquitetura e Agronomia da Bahia, Salvador, v.16, n.1, p.14-16, 2006.

RADOSAVLJEVIC, V.; JAKOVLJEVIC, B. Bioterrorism-types of epidemics, new epidemiological paradigm and levels of prevention. Public Health, Amsterdan, v.121, n.7, p.549-557, 2007.

ROFFEY, R.; TEGNELL, A.; ELGH, F. Biological warfare in a historical perspective. Clin Microbiol Infection, Oxford, v.8, n.8, p. 450-454, 2002.

RUTALA, W.A.; WEBER, D.J. Uses of inorganic hypochlorite (bleach) in health care facilities. Clin Microbiol Rev, Washington, v.10, n.4, p.597-610, 1997.

SILVA, L.J. Guerra biológica, bioterrorismo e saúde pública. Cad. Saúde Pública, Rio de Janeiro, v.17, n.6, p.1519-1523, 2001. 
SMART, J.K. History of chemical and biological warfare: an American perspective. In: FREDERICK, R.S.; TAKAFUJI, E.T.; FRANZ, D.R. (Eds.) Medical Aspects of Chemical and Biological Warfare. Washington:TMM Publications, 1997. p.9-86.

TAKAHASHI, H. et al. Bacillus anthracis Incident, Kameido, Tokyo, 1993. Emerg Infect Dis, Atlanta, v.10, n.1, p.117-120, 2004.

UNITED NATIONS. A More Secure World: our shared responsibilities. Report of the HighLevel Panel on Threats, Challenges and Change. New York: UN, 2004.

\section{Nota}

${ }^{1}$ D. Rambauske realizou a revisão da literatura, elaborou estratégias metodológicas e participou da construção do tema. T.A. de O. Cardoso ocupou-se dos conteúdos técnicos referentes ao potencial de letalidade de patógenos, observando a classificação de risco, e ainda participou da revisão da literatura adequada ao tema. M.B.M. de A. Navarro realizou a análise contextual do tema, observando as discussōes conceituais sobre bioterrorismo. 


\section{Abstract}

Bioterrorism, biological risks and biosafety measures applicable to Brazil

History records the use of pathogens as improvers of military resources. Considering the events of contemporary war, there is the formulation of projects aimed at sophisticated technological development. They shall include biological weapons, linked to coercive programs known as biological warfare, which belong to the logic of asymmetric threat, not defining territory and generating devastating economic, political and socio-psychological repercussions. These events require the preparation of plans that address the risk, including the training of human resources, investments in the identification of materials used in bioterrorism and also in safety equipment. This paper aims to discuss the association between pathogens, their potential risk and effectiveness for use in bioterrorism strategies, highlighting the necessary biosecurity measures. It uses an integrative review to construct contexts risk analysis. The literature included the period 1990/2010, the ISI databases, LILACS, SciELO and PubMed. It demonstrates the importance of the involvement and training of professionals in the identification of biological agents with potential risk, whereas bioterrorism may result in overload of health systems. Biosecurity guides the procedures to be adopted for the containment of pathogens, aimed at controlling risk.

> Key words: bioterrorism; biological agents; biosafety. 